ГORIGINAL ARTICLE -

Volume 14 Issue 22019

DOI: 10.21315/aos2019.14.2.355

ARTICLE INFO

Submitted: $08 / 11 / 2018$

Accepted: 18/09/2019

Online: 30/12/2019

\section{A Pilot Study of Preparedness for Medical Emergencies in Urban Private Dental Practices in Malaysia}

\author{
Nalisha Mohamed Ramli ${ }^{\star}$, Nor Azura Ahmad Tarmidzi ${ }^{\mathrm{a}}$, Ahmad \\ Dzulfikar Samsuddina, Nurul Izza Idaham ${ }^{b}$, Ahmad Zharif Ibrahim
}

${ }^{a}$ Department of Oral and Maxillofacial Surgery, Pathology and Medicine, Faculty of Dentistry, Universiti Sains Islam Malaysia, 55100 Kuala Lumpur, Malaysia

${ }^{b}$ Department of Periodontology and Community Oral Health, Faculty of Dentistry, Universiti Sains Islam Malaysia, 55100 Kuala Lumpur, Malaysia

'Department of Paediatric Dentistry and Orthodontics, Faculty of Dentistry, Universiti Sains Islam Malaysia, 55100 Kuala Lumpur, Malaysia

*Corresponding author: nalisha@usim.edu.my

To cite this article: Mohamed Ramli N, Ahmad Tarmidzi NA, Samsuddin AD, Idaham NI, Ibrahim AZ (2019). A pilot study of preparedness for medical emergencies in urban private dental practices in Malaysia. Arch Orofac Sci, 14(2): 99-111. https://doi.org/10.21315/aos2019.14.2.355

To link to this article: https://doi.org/10.21315/aos2019.14.2.355

\begin{abstract}
The aim of this study was to obtain data of medical emergencies at the non-hospital based private dental practices in Petaling district of Selangor, Malaysia. Ninety out of 281 identified main practitioners of non-hospital based private dental practices had agreed to participate. A standardised questionnaire forms consisting of four parts including demographic data, emergency equipment and drugs available, occurrence of medical emergencies and training of dental practitioners. All data retrieved were analysed using the Statistical Programme for Social Science (SPSS) version 22.0 (SPSS Inc., 1999). Some of the clinics $(28.9 \%)$ had reported experiencing medical emergencies events. The most common emergency event noted was syncope $(42.2 \%)$, followed by hypoglycaemia $(27.7 \%)$. Majority of the events occurred in the dental surgery room $(84.3 \%)$, after completion of treatment $(31.3 \%)$ and were associated with dental extraction procedures $(61.4 \%)$. Only nine of the clinics $(3.3 \%)$ were equipped with emergency trolley and none were prepared with a defibrillator or automated external defibrillator (AED). It was also found that $32.3 \%$ of all clinics do not have any emergency drugs. All of the practitioners received basic life support training before graduation and $52.2 \%$ received supplementary training after graduation. In conclusion, emergency medical events do occur, but majority of dental practices involved in this study were not well equipped to manage these emergencies. It is important to have a standardised national guideline to ensure a safe and well-prepared dental setting during any adverse medical events.
\end{abstract}

Keywords: Dental practice; emergency drugs; emergency equipment; medical emergencies; private dental practice. 


\section{INTRODUCTION}

Retention of natural teeth, increasing number of chronic medical illnesses and the increase in life expectancy has resulted in more medically compromised patients expected in dental practices (Atherton et al., 1999a; Smeets et al., 1999; Joshi and Acharya, 2015). Medical emergencies in dental practice may be considered as rare events but it can be fatal if not managed properly (Atherton et al., 1999b; Reuter et al., 2017). The total prevalence of all emergency events in the United Kingdom (UK) was recorded as 0.7 cases per dentist per year (Girdler and Smith, 1999). Another report from the UK had stated that it occurs with an average frequency between 1 in 3.6 and 4.5 practice years, or on average between 9 and 11 emergency events per practicing lifetime of 40 years with associated death of once in 758 and 464 years (Atherton et al., 1999a). Similarly in Fiji Island, 226 emergency events were recorded giving a mean of 3.42 events per respondent, per 10 years (Morse and Murthi, 2004). In a study involving 1,344 dentists in France, the emergencies incidences were 2.1 events per dentist per year (Laurent et al., 2014). Meanwhile, in South Africa and Slovenia, it was reported that their dentists had experienced medical emergencies as $19 \%$ and 93.4\% respectively (Qwen and Mizra, 2015; Umek and Šoštarič, 2018).

The frequencies of medical emergencies in dental clinics were reported as $27.9 \%$ for fainting, followed by postural hypotension (23.5\%), hypoglycaemia (19.5\%), epileptic fits and seizure (11.1\%), asthma (8\%), angina pectoris $(5.3 \%)$, inhaled foreign body $(2.2 \%)$, cardiac arrests $(1.8 \%)$, respiratory obstruction (0.4\%) and anaphylactic reaction $(0.4 \%)$ (Morse and Murthi, 2004; Shah et al., 2016). Both articles did not specify the dental treatments associated with these events but according to Atherton et al. (1999a), most medical emergencies were noted to occur during conservative dental treatments and dentoalveolar surgery. Emergency drugs and equipment necessary in a dental surgery for any medical emergency have been recommended by a number of authorities (Chapman, 1997; Hass, 2006). Haas (2006) divided the drugs into two categories; essential and additional emergency drugs.

A survey among dentists in Australia discovered that oxygen was the commonest item kept by $63 \%$ of the respondent (Chapman, 1997). Other published papers have stated that sphygmomanometer is the most available equipment in the dental office (Morse and Murthi, 2004; Qwen and Mizra, 2015). Approximately, $14 \%$ of the practitioners did not keep any of the emergency drugs or equipment (Chapman, 1997). On the other hand, a study in South Africa reported only $1 \%$ of its practitioners had all the equipment required to deal with medical emergencies in their practice (Qwen and Mizra, 2015). In France, 19.2\% dentists declared of not having any emergency equipment available in their clinics (Laurent et al., 2014).

Few studies have also assessed how competent dentist consider themselves in managing medical emergencies. A questionnaire survey in Australia found that two-thirds of respondents felt that they could carry out expired air resuscitation and that over half $(55 \%)$ believed themselves to be competent in cardiopulmonary resuscitation (CPR). Meanwhile 64\% had undertaken CPR course since graduation (Chapman, 1997). In Great Britain, majority of the respondents $(78.7 \%)$ felt that they were prepared to manage a medical emergency, and this were the group who possess the emergency drugs and equipment necessary to do so (Atherton et al., 1999b).

To the best of our knowledge, there are limited number of published information regarding medical emergencies related to dental visits in Malaysia. In order to minimise morbidity and mortality of patients, dental practices must be properly equipped with relevant drugs and equipment to initiate emergency intervention. Even though medical emergency events are relatively uncommon in the dental settings, 
their seriousness cannot be underestimated with potentially grave consequences. Therefore, the aim of the present study was to obtain data of medical emergencies occurring in the non-hospital based private dental practices located in the Petaling district of Selangor, Malaysia. This study was designed to provide a baseline data on the prevalence and type of medical emergencies experienced by these practitioners. It was also designed to give an overall view of the availability of emergency drugs and equipment in the private dental settings. Furthermore this study was aimed to investigate the training received by the practitioners regarding medical emergencies and their perceived competency to manage such cases as a dental professional.

\section{MATERIALS AND METHODS}

This was a cross sectional study involving private dental practitioners in Petaling district of Selangor, Malaysia. A total of 281 non-hospital based private dental clinics were listed and registered to the Malaysian Dental Council in the Petaling district of Selangor during the study period from January to August 2016. Ninety of the 281 practitioners had consented to participate in the study, resulting in a response rate of $32 \%$. This study employed a total population sampling method to maximise the response rate received from the respondents.

The inclusion criteria are the resident (main) private dental practitioners practicing in the non-hospital based private dental clinics in Petaling district of Selangor involving both general dental practitioners and those with specialist qualifications. Clinics that are located within a hospital settings and government dental clinics were excluded from this study.

A standardised validated questionnaire forms adapted from Atherton et al. (1999a; 1999b) was used for this study. The questionnaire was divided into four main parts. The first part dealt with the demographic data of practitioner's background, qualification, incident reporting method and types of treatment provided. The second part of the questionnaire was regarding the emergency equipment and drugs available in the clinics, which respondents select from the available listed items. The third part was related to the occurrence of medical emergencies in the dental practice. Respondents need to specify the types of emergency event, venue of the event, treatment stage/procedure when the event occurred, and specific management done. The final part of the questionnaire was about training or competency of the dental practitioners whereby respondents evaluated their own perceived ability to manage medical emergencies based on two dimensions; training they received during the undergraduate courses and in the current dental practice. They need to indicate their perception based on a five-scale rating which are "very well", "fairly well", "moderate", "not very well" and "not at all".

The questionnaire was pre-tested prior to data collection to identify any flaws in the items that need to be altered to facilitate the participants' response. There were no changes made to the questionnaire subsequent to the pre-test. A research information sheet detailing the aim of the study, objectives, research procedures, duration of project, participant selection, benefits, confidentiality assurance as well as the main researcher's contact details were included. Respondents were required to sign a written consent form attached with the information sheet. In order to conduct the study, ethical approval has been obtained from the Medical Ethics Committee, Faculty of Dentistry, Universiti Sains Islam Malaysia (Code MEC: USIM/FPg-MEC/ DAV4014/2014/No. (11)).

In the first stage of data collection, the lists of private non-hospital based dental clinics at Petaling district of Selangor were identified. A number of 281 sets of questionnaires, research information sheet and consent form were posted to the clinic address and were intended to be filled by either the main resident dental practitioner of the clinic or its practising owner. A pre-paid reply envelope was also given for the participants to respond 
to the investigators. A reminder letter was given in accordance to no response received between three to six months of questionnaire postage. The poor response rate via postage was noted and there were questionnaires received as incomplete and need to be excluded. Only 18 questionnaires were returned back to the investigators and five need to be excluded.

In order to overcome the poor response rate, enumerators were appointed to distribute the questionnaires in each clinic listed as a non-hospital based private dental practitioners in Petaling district of Selangor. Ninety completed questionnaires managed to be collected from the consented respondents. Data were analysed using the Statistical Programme for Social Science (SPSS) version 22.0 (SPSS Inc., 1999). Descriptive statistics were done. Categorical variables were calculated as frequency and percentages.

\section{RESULTS}

Ninety of the 281 dental practices had agreed to participate and responded to the questionnaires leading to a response rate of $32 \%$. All of the dental clinics provided treatment under local anaesthesia and two clinics provided treatment under intravenous sedation $(1.1 \%)$ and oral sedation $(1.1 \%)$ respectively. Two other clinics $(2.2 \%)$ have inhalation sedation service available for dental treatment. Majority of the clinics had proper incident recording systems. Methods used for record keeping of medical emergency events include incident reporting book, patient's folder and computerised database system.

\section{Emergency Equipment and Drugs}

Nearly half of the participated clinics $(46.7 \%)$ had blood pressure monitoring device. Ten percent had glucometer and $11.1 \%$ had stethoscope available in their clinics. Nine clinics (3.3\%) were equipped with emergency trolley but none of the clinics were prepared with a defibrillator or automated external defibrillator (AED) (Fig. 1). Most clinics had oral glucose and chlorpheniramine (antihistamine) available as emergency drugs. Only one clinic was noted to have almost all the emergency drugs listed except chlorpheniramine, atropine and naloxone. Twenty-nine clinics $(32.2 \%)$ do not have any emergency drugs available in their practices. The types of drugs availability are shown in Fig. 2.

\section{Emergency Events}

Some of the participated clinics (28.9\%) had experienced medical emergency events in their practice. Two clinics $(2.22 \%)$ had more than ten medical emergencies events. Four of the clinics with medical emergencies incidence $(4.45 \%)$ did not equipped themselves with any emergency equipment or drugs. The most common emergency events noted were syncope (42.2\%) followed by hypoglycaemia $(27.7 \%)$. Other reported events included drug reactions $(13.3 \%)$, epilepsy $(9.6 \%)$, inhaled foreign body (3.6\%), anaphylaxis (2.4\%) and myocardial infarction (1.2\%). Most of the emergency events occurred in the dental surgery room $(84.3 \%)$ (Table 1 ). According to the responses received, the most medical emergencies occurred upon completion of dental procedure or treatment $(31.3 \%)$ and after local anaesthesia administration $(25.3 \%)$ (Table 2). Majority of the emergency events were associated with dental extraction procedures, a total of 51 cases $(61.4 \%)$, followed by 11 cases associated with drugs administration (13.3\%) (Fig. 3).

\section{Training and Perceived Competency of Dental Practitioners}

All of the practitioners had training in the management of medical emergencies during the undergraduate dental courses. Eighty percent had undergone basic life support or CPR courses, $38.9 \%$ had been trained to use emergency drugs, $28.9 \%$ were trained to use emergency equipment and only $18.9 \%$ had been trained to gain intravenous access. 


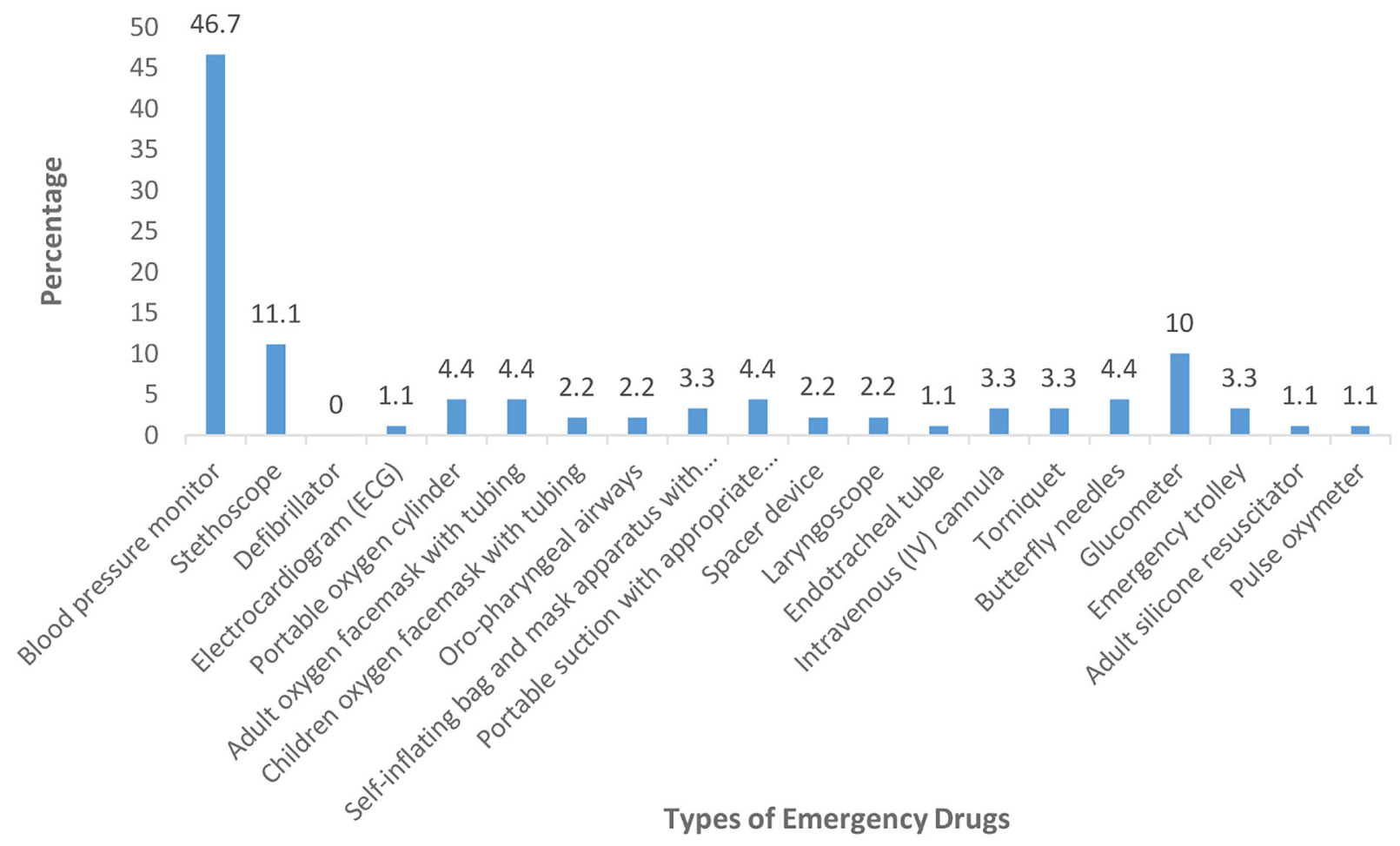

Fig. 1 Availability of emergency equipment in private dental clinics.

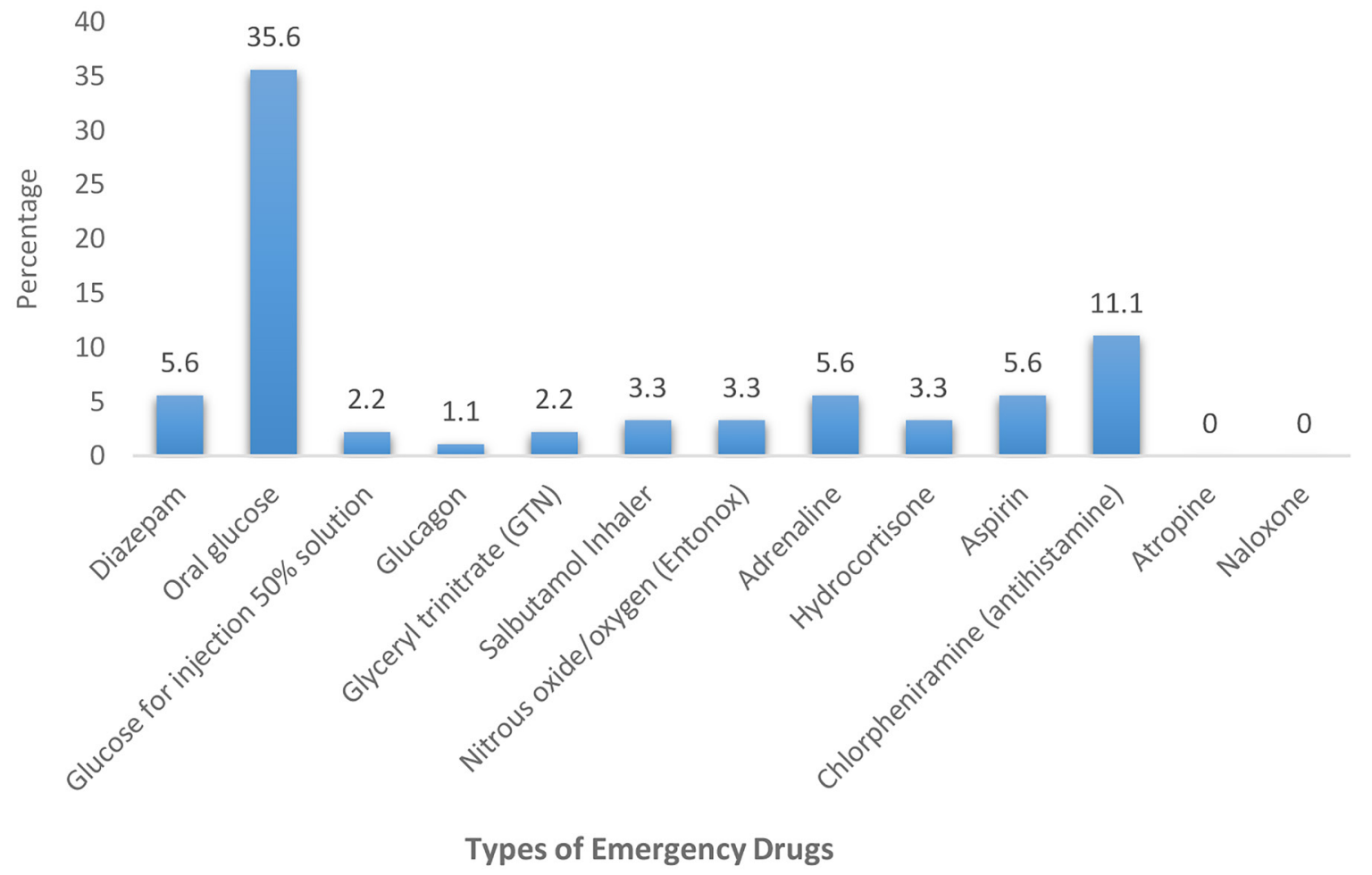

Fig. 2 Availability of emergency drugs in private dental clinics. 
Table 1 Proportion of medical emergencies in non-hospital based private dental practice in Petaling district of Selangor, Malaysia

\begin{tabular}{|c|c|c|c|c|c|}
\hline \multirow[b]{2}{*}{ Emergency event } & \multirow{2}{*}{$\begin{array}{c}\text { Number of clinics } \\
\text { n (\%) }\end{array}$} & \multirow{2}{*}{$\begin{array}{c}\text { Number of } \\
\text { events } \\
\text { n (\%) }\end{array}$} & \multicolumn{3}{|c|}{ Location } \\
\hline & & & $\begin{array}{c}\text { Surgery } \\
\text { n (\%) }\end{array}$ & $\begin{array}{c}\text { Waiting room } \\
\text { n (\%) }\end{array}$ & $\begin{array}{c}\text { Patient's home } \\
\text { n (\%) }\end{array}$ \\
\hline Syncope & $16(19.3)$ & $35(42.2)$ & $33(39.8)$ & $2(2.4)$ & 0 \\
\hline Epilepsy & $5(6)$ & $8(9.6)$ & $8(9.6)$ & 0 & 0 \\
\hline Hypoglycemia & $8(9.6)$ & $23(27.7)$ & $23(27.7)$ & 0 & 0 \\
\hline Inhaled foreign body & $3(3.6)$ & $3(3.6)$ & $3(3.6)$ & 0 & 0 \\
\hline Myocardial Infarction & $1(1.2)$ & $1(1.2)$ & $1(1.2)$ & 0 & 0 \\
\hline Anaphylaxis & $2(2.4)$ & $2(2.4)$ & $1(1.2)$ & 0 & $1(1.2)$ \\
\hline Drug reactions & $6(7.2)$ & $11(13.3)$ & $1(1.2)$ & 0 & $10(12.1)$ \\
\hline Total & $41(49.3)$ & $83(100)$ & $70(84.3)$ & $2(2.4)$ & $11(13.3)$ \\
\hline
\end{tabular}

Table 2 Stages of dental treatment involved with medical emergencies

\begin{tabular}{|c|c|c|c|c|c|}
\hline Emergency event & $\begin{array}{c}\text { Before } \\
\text { treatment } \\
\text { n (\%) }\end{array}$ & $\begin{array}{c}\text { After local } \\
\text { anaesthesia } \\
\text { n (\%) }\end{array}$ & $\begin{array}{c}\text { During the } \\
\text { procedure } \\
\text { n (\%) }\end{array}$ & $\begin{array}{l}\text { After the } \\
\text { procedure } \\
\text { n (\%) }\end{array}$ & $\begin{array}{c}\text { Medicine taken at } \\
\text { home } \\
\text { n (\%) }\end{array}$ \\
\hline Syncope & $3(3.6)$ & $14(16.9)$ & $7(8.4)$ & $11(13.3)$ & 0 \\
\hline Epilepsy or seizures & $2(2.4)$ & $4(4.8)$ & $1(1.2)$ & $1(1.2)$ & 0 \\
\hline Hypoglycemia & $10(12.1)$ & $2(2.4)$ & $6(7.3)$ & $5(6)$ & 0 \\
\hline Inhaled foreign body & 0 & 0 & $3(3.6)$ & 0 & 0 \\
\hline Myocardial Infarction & $1(1.2)$ & 0 & 0 & 0 & 0 \\
\hline Anaphylaxis & 0 & $1(1.2)$ & 0 & 0 & $1(1.2)$ \\
\hline Drug reactions & 0 & 0 & 0 & $9(10.8)$ & $2(2.4)$ \\
\hline Total & $16(19.3)$ & $21(25.3)$ & $17(20.5)$ & $26(31.3)$ & $3(3.6)$ \\
\hline
\end{tabular}

More than half of the practitioners $(52.2 \%)$ who had received supplementary training in their current dental practices were trained in basic life support or CPR. Thirty percent had been trained to use emergency drugs, $28.9 \%$ to use emergency equipment and only $16.7 \%$ had been trained to gain intravenous access (Fig. 4). Based on the undergraduate training received, $73.6 \%$ claimed to have moderate competency or preparedness for managing medical emergencies. However, $4.2 \%$ felt they were not at all prepared or competence in managing such cases. Among the respondents who had received training for medical emergencies after they graduated, $51.1 \%$ claimed to be fairly well in competency or preparedness and $48.9 \%$ felt to be moderately competent in medical emergencies management.

\section{DISCUSSION}

The response rate $(32 \%)$ in the present study was lower compared to other studies done in Australia at 65\% (Chapman, 1997), Great Britain, 74\% (Atherton et al., 1999a), Fiji, 85.7\% (Morse and Murthi, 2004) and Saudi Arabia, 81.8\% (Al-Turki et al., 2017) but comparable to a study in Britain, 34\% (Girdler and Smith, 1999). A lower response rate of $10.5 \%$ from South Africa was also previously reported (Qwen and Mizra, 2015). The previous studies included both government and private dental practices, but the present study only focused to the non-hospital based private dental practices in Malaysia. The government dental clinics in Malaysia are usually located in the close vicinity or in the same compound with the 


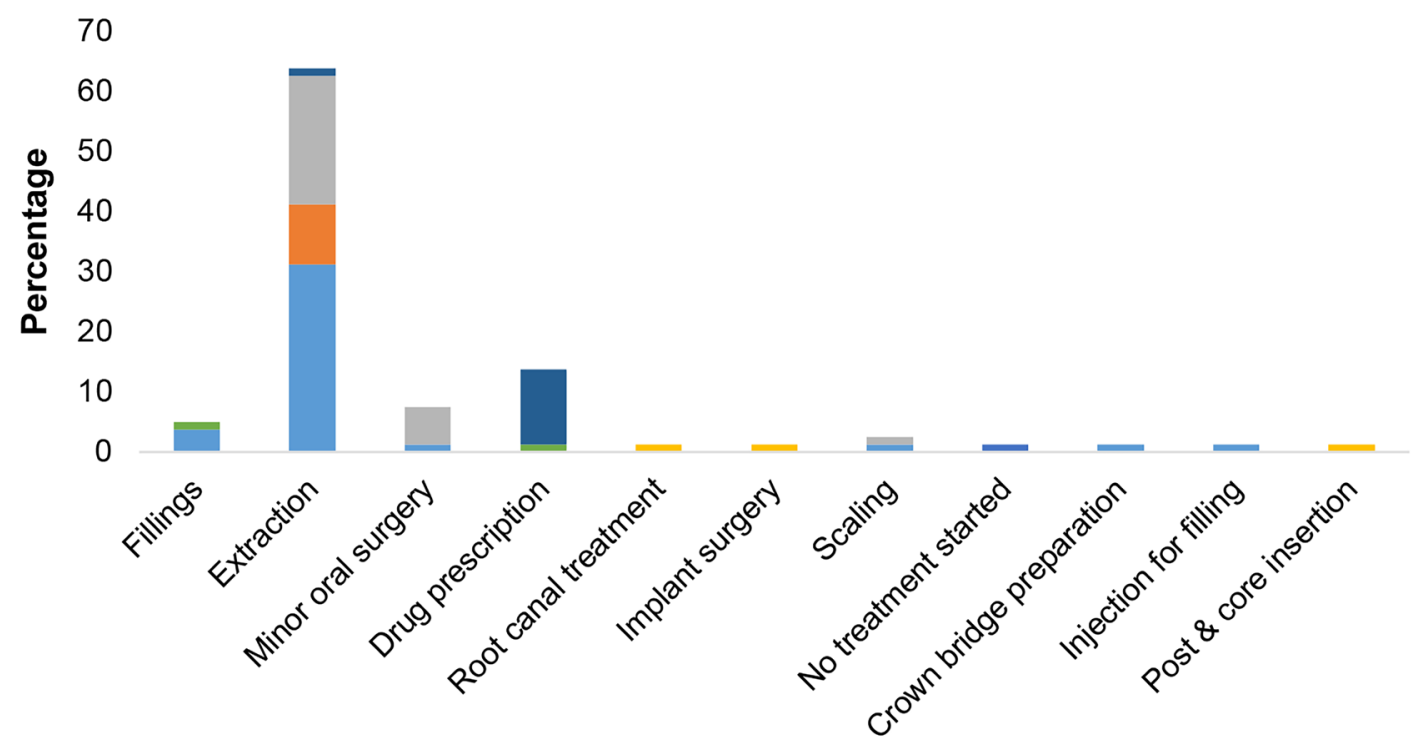

Type of Dental Procedures
- Syncope
Epilepsy or Seizures $\square$ Hypoglycemia
- Inhaled foreign body
- Myocardial Infarction $₫$ Anaphylaxis
- Drug reactions

Fig. 3 Percentage of medical emergencies in various dental procedures.

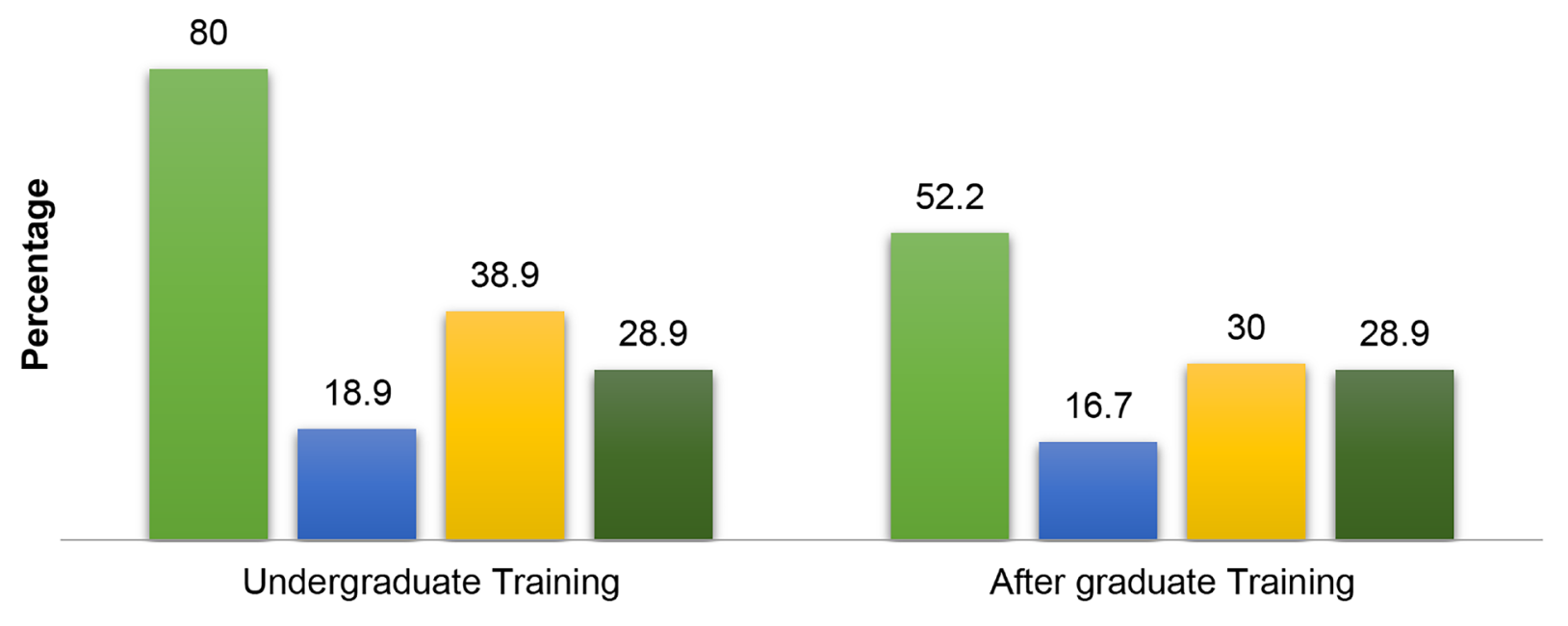

Type of Training Received

- Basic Life Support

- Gaining IV access

- Use of emergency drugs

- Use of emergency equipment

Fig. 4 Training for management of medical emergencies among dental practitioners. 
health clinics. As such, the hospital based dental clinics will have optimum access to the emergency facilities of its hospital. Hence, those dental practices are not included in the present study. Additionally, the lower response rate might be caused by the practitioners feeling insecure to disclose their lack of equipment and drugs making them refused to participate in the study.

Even though medical emergencies were considered rare in the dental office, they did occur and could even cause death of patients (Atherton et al., 1999a; Reuter et al., 2017). In the present study, $28.9 \%$ had experienced medical emergencies but this finding was not based on any specific practice years or period of time. A more frequent events of once for every three practice years were previously reported (Morse and Murthi, 2004). Albeit the small percentage, the fact that it did occur is an eye opener to dental professionals especially those in the private practices. However, it should be eminent that the emergency events in the present study were not accounted for specific period of operating years and does not represent the occurrence of medical emergencies incidents for Malaysian dental services generally.

All the participated clinics provided dental treatment under local anaesthesia with few clinics provided treatment under inhalation sedation $(2.2 \%)$, oral sedation $(1.1 \%)$ and intravenous sedation (1.1\%). As previously mentioned, the government hospital based dental practices where sedation services are more likely to be offered along with general anaesthesia were not included in the present study. Treatment provided under general anaesthesia, both intravenous and inhalation sedation had more emergency events reported than those without it (Atherton et al., 1999a). On the other hand, in the present study, no medical emergencies event was noted to occur in any of the dental clinics that provided dental treatment under intravenous and inhalation sedation. Unfortunately these clinics were also noted not to have any emergency equipment and drugs available.
In the present study, syncope was the commonest emergency event which was favourable with results of other studies done in Great Britain (Atherton et al., 1999a; Girdler and Smith, 1999), Fiji (Morse and Murthi, 2004), India (Jodalli and Ankola, 2012), France (Laurent et al., 2014), South Africa (Qwen and Mizra, 2015), Nepal (Joshi and Acharya, 2015) and Saudi Arabia (AlTurki et al., 2017). Although syncope was not considered strictly as an 'emergency', it still requires prompt and correct treatment, or otherwise it can lead to a more adverse sequelae such as cerebral ischaemia (Girdler and Smith, 1999). The cause of syncope was not clear as it could either be due to dental phobia or might be associated with hypoglycaemic event (Girdler and Smith, 1999). Hypoglycaemia itself was found to be the second most common emergency events in the present study. The other most common events were drug reaction, epilepsy, inhaled foreign body, anaphylaxis and myocardial infarction. Although only one myocardial infarction event was reported, it was the only event that resulted in death at the dental office before arrival of emergency medical services.

Oral glucose is the most common emergency drug available in the participated clinics. Approximately $32.2 \%$ of the clinics do not have any emergency drugs or equipment at all which are much higher compared to previous survey done in Australia that reported $14.4 \%$ of dentists with neither emergency drugs nor equipment available in their dental offices (Chapman, 1997). A more recent study in South Africa claimed that less than $3 \%$ of their dentists possessed all the recommended emergency drugs required while $32 \%$ had none of the recommended drugs (Qwen and Mizra, 2015). Haas (2006) had recommended the minimum requirement and essential drugs to adequately manage medical emergency, but none of the drugs were available by more than 10 clinics.

In regard of the availability of equipment, most clinics were equipped with glucometers 
and stethoscopes. Only nine clinics were equipped with emergency trolley but none of the clinics were prepared with a defibrillator or AED. One clinic was noted to have been equipped with most of the emergency equipment listed in the questionnaire except defibrillator, oropharyngeal airways and emergency trolley. Only $10 \%$ of dentists in South Africa were found to have at least half of the emergency equipment recommended and even a smaller percentage of $1 \%$ of its respondents stated to have all the equipments required (Qwen and Mizra, 2015). These findings were in accordance with the previous report from France where $19.2 \%$ of the dentists declared of not having any emergency equipment available in their clinics (Laurent et al., 2014).

The New Zealand Dental Council (2016) listed several drugs and equipment for practitioners administering sedation in their clinics. These include antagonists for sedative drugs, dextrose $10 \%$, glucagon, normal saline, advance airway adjuncts, equipment for intravenous access and AED. The National Dental Advisory Committee (2015), of the Scottish Government, added flumazenil in the list for dental settings where conscious sedation is available using benzodiazepines. Additional emergency equipment was also required including pulse oximeter, blood pressure monitor and nasal cannula set. All these guidelines have taken into consideration the need as well as capability of a dental surgeon to use the equipment and drugs listed. We recommend a standardised national protocol to synchronise the management of medical emergencies in dental practices particularly the non-hospital based private dental practices as well as to ensure the availability of emergency drugs and equipment in the dental office.

In the present study, it was found that five out of six emergency events occurred in the dental surgery which is comparable to a previous study with nearly four out of five events (Atherton et al., 1999a). It was also noted that eight emergency events occurred at home after dental treatment and all cases were related to drug reaction with one case of anaphylaxis. Hence, it is worth to note that medical emergencies events can also affect patients returning from dental treatment mainly related to the drugs prescribed (Atherton et al., 1999a). It is advisable to give clear instruction to the patient of the need to immediately inform the clinic in case of any adverse reaction at home. Unfortunately, we could not relate the occurrence of all these events to the patient's medical condition.

Thirty one percent of the emergency events occurred after dental procedure, which were different from findings of previous study that found $36.7 \%$ occurred during the dental procedure (Atherton et al., 1999a). The second most common procedure related to occurrence of medical emergencies was after the local anaesthesia administration. Most of the events happened during dental extraction procedure, which was again different from the previous study done in Great Britain, where more than half of the events occurred during dental fillings (Atherton et al., 1999a). Half of the emergency events during extraction was syncope followed by hypoglycaemia and epilepsy. In a previous report, medical emergencies occurred mainly during treatment and during extraction and minor oral surgical procedure, which implied that exodontia was associated with significant psychological and physiological stress (Joshi and Acharya, 2015).

More than two thirds of the respondents had received undergraduate training for management of medical emergencies while only half had received the training after they graduated. Among those who had received undergraduate training, $4.2 \%$ still think that they were not prepared to deal with these situations. All respondents who received both undergraduate and after graduation training claimed to have acquired basic life support training. The only way of achieving competence in emergency management is by undergoing structured Basic Life Support (BLS) course conducted by qualified 
instructors (Chapman, 1997; Maluvelil and Kathavate, 2016). Dental personnel must be prepared to provide effective BLS and seek emergency medical services in a timely manner. Dentists must also be able to diagnose and treat common emergency problems as well as respond effectively to certain less common but potentially lifethreatening emergencies (Rosenberg, 2010).

The knowledge of basic life support among dentists will help them provide immediate emergency care whilst waiting for the definitive medical assistance (Carvalho et al., 2008). A previous study had revealed that majority of dental graduates has lack of knowledge in managing medical emergencies even with the training received during undergraduate study and expressed the need for further training (Jodalli and Ankola, 2012). The competency in the management of basic life support will deteriorate after 18 months of training (Chate, 1996). The National Committee on Resuscitation Training (NCORT) (2012) in Malaysia recommended skills refresher course of basic life support to be undertaken more often than the current recommended training interval of 12 to 24 months. Another recommendation from a local publication suggested that dental practitioners and their supporting staff must undergo a recertification of basic life support training every two to three years (Ngeow et al., 2015).

Nevertheless, basic life support training per se is not enough to manage these emergencies. Traditionally, emergency training for dentists were concentrated on basic life support for cardiac arrest management but the incidence of other medical emergencies outweighs that of cardiac origin (Fletcher and Kramer, 1992; Girdler and Smith, 1999; Atherton et al., 1999b; NCORT, 2012). Hence, an adequate knowledge in identifying and managing emergency medical events during dental visits are crucial to be incorporated in dental undergraduates' curriculum. This knowledge must also be obtained consistently and made accessible throughout the professional career of a dentist. The Internet and online training can be a useful platform to provide more training for these practitioners. The medical communities can also contribute to their dental counterparts by sharing their output to manage medical emergencies effectively. More opportunity for professional development should be made available for dental practitioners to rekindle their knowledge and skills.

It is indeed important that dental practitioners received adequate training in the use of drugs and equipment they might use during the medical emergencies (Chate, 1996). Their skills and knowledge should not only be realistic in terms of training but also in considering the number of times these skills are likely to be used in their professional career. Wilson et al. (2009) suggested an algorithm for the management of medical emergencies to be adapted in dental practice. The algorithm provides guidance in specific responses to emergency situations and all staff must undergo training of emergencies to a level based on their clinical responsibilities. The skills should be refreshed annually, and a regular clinical audit is conducted (Wilson et al., 2009).

Development of a standardised national guideline and checklist is mandatory to ensure the preparedness of dentists in managing medical emergencies and avoiding any unnecessary mortality. The authors have also suggested a simple flow chart of algorithm that can be adopted by nonhospital based dental practitioners in any event of medical emergencies (Fig. 5). We proposed a protocol that is easy to be implemented by all dental practitioners in order to ensure that their initial emergency medical response is practical and most importantly lifesaving. Re-evaluation of education on emergency care and basic life support to dental practitioner particularly in terms of continuous educational programme should be considered. An interactive evidence-based learning and training guide can be a good option for knowledge transfer in the era of modern dentistry in order to ensure safe practice. 


\section{CONCLUSION}

Even though medical emergencies do actually occur in our dental offices, majority of the non-hospital based private dental practices involved in this study were still not well equipped to manage medical emergencies. It is important to have a standardised national guideline for all professional dental services to ensure safe and well-prepared dental settings during any adverse medical events. The authors would also like to recommend a larger populationbased study in the near future to determine the exact prevalence or incidence of medical emergencies events of dental practices in Malaysia.

\section{ACKNOWLEDGEMENTS}

This research is funded by Short Term Grant of Universiti Sains Islam Malaysia (PPP/ USG-0114/FPG/30/10914)

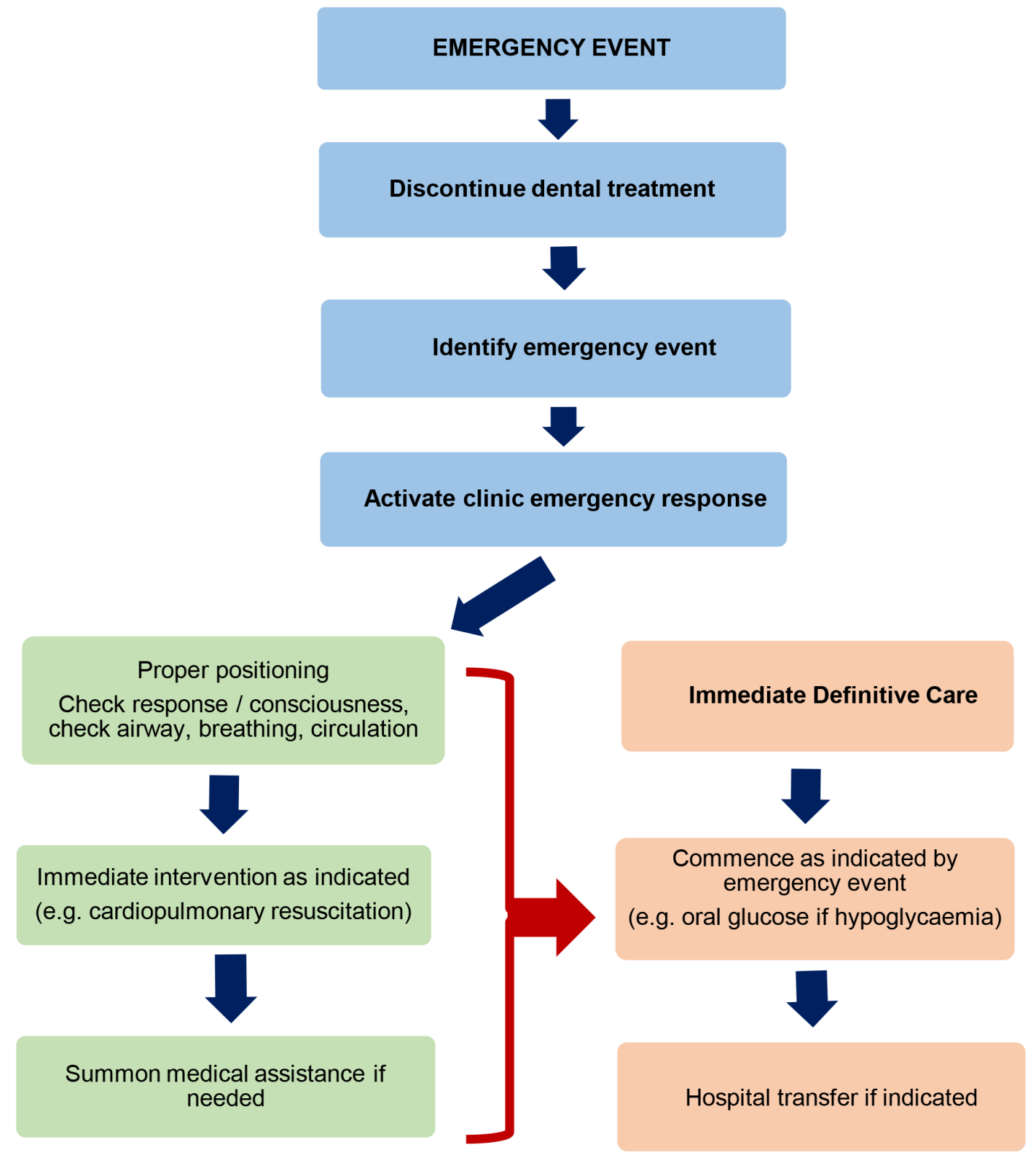

Fig. 5 Recommended algorithm on medical emergency response in non-hospital based private dental practices in Malaysia. 


\section{REFERENCES}

Al-Turki OY, Al-Hussyeen AA, Al-Hammad NS, Alhowaish L, Almaflehi N (2017). Medical emergencies in dental practice (Part 1: Prevalence and factors associated with their number and occurrence in Riyadh). IOSR f Dent Med Sci, 16(12): 1-9. https://doi. org/10.9790/0853-1612080109.

Atherton GJ, McCaul JA, Williams SA (1999a). Medical emergencies in general dental practice in Great Britain. Part I: Their prevalence over a 10-year period. $\mathrm{Br}$ Dent f, 186(2): 72-79. https://doi.org/10.1038/ sj.bdj. 4800023 .

Atherton GJ, McCaul JA, Williams SA (1999b). Medical emergencies in general dental practice in Great Britain. Part 3: Perceptions of training and competence of GDPs in their management. $\mathrm{Br}$ Dent $\mathcal{F}$, 186(5): 234-237. https://doi.org/10.1038/ sj.bdj.4800073.

Carvalho RM, Costa LR, Marcelo VC (2008). Brazilian dental students' perceptions about medical emergencies: A qualitative exploratory study. $\mathcal{f}$ Dent Educ, 72(11): 1343-1349.

Chapman PJ (1997). Medical emergencies in dental practice and choice of emergency drugs and equipment: A survey of Australian dentists. Aust Dent f, 42(2): 103-108. https://doi. org/10.1111/j.1834-7819.1997.tb00104.x.

Chate RA (1996). Evaluation of a dental practice cardiopulmonary resuscitation training scheme. Br Dent F, 181(11-12): 416-420. https://doi.org/10.1038/sj.bdj.4809279.

Fletcher JM, Kramer LD (1992). An in-practice training scheme for cardiopulmonary resuscitation (CPR). $\mathrm{Br}$ Dent $\mathcal{F}$, 172: 252-253. https://doi.org/10.1038/ sj.bdj. 4807840 .
Girdler NM, Smith DG (1999). Prevalence of emergency events in British dental practice and emergency management skills of British dentists. Resuscitation, 41(2): 159-167. https://doi.org/10.1016/s03009572(99)00054-4.

Haas DA (2006). Management of medical emergencies in the dental office: Conditions in each country, the extent of treatment by the dentist. Anesth Prog, 53(1): 20-24. https://doi.org/10.2344/00033006(2006)53[20:MOMEIT]2.0.CO;2.

Jodalli PS, Ankola AV (2012). Evaluation of knowledge, experience and perceptions about medical emergencies amongst dental graduates (Interns) of Belgaum City, India. f Clin Exp Dent, 4(1): e14-e18. https://doi. org/10.4317/jced.50627.

Joshi S, Acharya S (2015). Medical emergencies in dental practice: A Nepalese study. Orthod f Nepal, 5(2): 33-37. https://doi. org/10.3126/ojn.v5i2.15223.

Laurent F, Augustin P, Youngquist ST, Segal N (2014). Medical emergencies in dental practice. Med Buccale Chir Buccale, 20: 3-12. https://doi.org/10.1051/ $\mathrm{mbcb} / 2013104$.

Maluvelil AM, Kathavate RN (2016). Management of medical emergencies in dental practice: A review. IFSS Case Rep Rev, 2(9): 33-36. https://doi.org/10.17354/ $\mathrm{cr} / 2016 / 193$.

Morse Z, Murthi VK (2004). Medical emergencies in dental practice in the Fiji Islands. Pac Health Dialog, 11(1): 55-58.

National Committee on Resuscitation Training (NCORT), Ministry of Health Malaysia (2012). Guidelines for Resuscitation Training: In Ministry of Health Malaysia Hospitals E Healthcare Facilities. Putrajaya: Ministry of Health Malaysia, pp. 39. 
National Dental Advisory Committee, The Scottish Government (2015). Emergency Drugs and Equipment in Primary Dental Care. Edinburgh: The Scottish Government, pp. 5.

New Zealand Dental Council (2016). Medical Emergencies in Dental Practice - Practice Standard. Wellington: New Zealand Dental Council, pp. 9.

Ngeow WC, Lim D, Ng CS, Chai WL (2015). The management of unexpected events in a general dental practice. Malays Dent $\mathcal{F}$, 38(2): 5-15.

Qwen CP, Mizra N (2015). Medical emergencies in dental practices in South Africa. $S A f r$ Dent F, 70(7): 300-303.

Reuter NG, Westgate PM, Ingram M, Miller CS (2017). Death related to dental treatment: A systematic review. Oral Surg Oral Med Oral Pathol Oral Radiol, 123(2): 194-204. https://doi.org/10.1016/j.oooo.2016.10.0.

Rosenberg M (2010). Preparing for medical emergencies: The essential drugs and equipment for the dental office. $\mathcal{F} \mathrm{Am}$ Dent Assoc, 141(Suppl1): 14S-19S. https://doi. org/10.14219/jada.archive.2010.0351.
Shah R, Venkatesh C, Patel P, Makadia N (2016). Medical emergencies in dental clinic. I Res Med Dent Sci, 4(1): 18-20. https://doi.org/10.5455/jrmds.2016413.

Smeets EC, Keur I, Oosting J, Abraham-Inpijn L (1999). Acute medical complications in 277 general dental practices. Prev Med, 28(5): 481-487. https://doi.org/10.1006/ pmed.1998.0448.

Umek N, Šoštarič M (2018). Medical emergencies in dental offices in Slovenia and readiness of dentists to handle them. Signa Vitae, 14(1): 43-48. https://doi. org/10.22514/SV141.032018.7

Wilson MH, McArdle NS, Fitzpatrick JJ, Stassen LF (2009). Medical emergencies in dental practice. F Ir Dent Assoc, 55(3): 134-143. 